\title{
A perspective of pipejacking works by tunnel boring machines in Hong Kong: part II - applications, problems encountered, cost and prospects
}

\author{
Wilson W S Mok ${ }^{1}$ and Andrew S W Ng ${ }^{2}$ \\ ${ }^{1}$ Independent Trenchless Consultant, Hong Kong, People's Republic of China \\ ${ }^{2}$ Victory Trenchless Engineering Company Limited, Hong Kong, People's Republic of China
}

\begin{abstract}
In this paper, application of special techniques such as pipe roof construction, retractable TBM, and rectangular TBM to address site difficulties and constraints is highlighted. Cost and prospects of TBM pipejacking works are discussed. Some observations, including problems encountered and overcome, are also highlighted. This paper should be read together with part I, which covers development, selection of design, operations and types of techniques.
\end{abstract}

KEYWORDS Sub-sea tunnel; pipe roof construction; retractable TBM; rectangular TBM; submarine pipelines CONTACT Wilson W S Mok wilsonwsmok@netvigator.com

Received 28 March 2021

\section{Other applications of pipejacking by tunnel boring machine (TBM)}

\subsection{Subsea tunnel passing below the seabed of Kai Tak approach channel}

Twin 2,800 $\mathrm{mm}$ diameter pipelines, each $350 \mathrm{~m}$ long, were constructed using a slurry-operated TBM (Figures 1a and $1 \mathrm{~b}$ ) below the $230 \mathrm{~m}$ wide seabed with an overburden of $10 \mathrm{~m}$. The depth of the two pipelines in the land side is $25 \mathrm{~m}$. In driving the first pipeline, the overcut formed by the TBM was rapidly closed by the seawater pressure, which induced high frictional force on the pipeline when it had completed a length of $140 \mathrm{~m}$. It caused difficulties in pushing the pipeline forward despite the activation of all four intermediate jacking stations. To resolve the problem, polymer, a substance that better bonds with soil particles, was used and continuously injected in the overcut, and auxiliary intermediate jacking stations were installed and repeatedly operated at the problem locations. The situation was rectified and did not recur after jacking the pipeline round the clock. (Mok et al., 2018; Mok et al., 2019)

\subsection{Running two TBMs in parallel}

Keeping up progress is always a concern in a contract. TBM pipejacking works always face a problem in the time required to locate a space both suitable and large enough for construction of a jacking/receiving pit. To mitigate the delay and stay on schedule, two TBMs of 1,500 mm diameter were deployed to run in parallel in a district cooling main project in Kai Tak district. The second TBM was launched after the first TBM had advanced $20 \mathrm{~m}$ to avoid interference with each other, and to minimise disturbance to the overlying ground and roads (Figure 2). The work was completed smoothly with the ground settlement controlled within the tolerated $20 \mathrm{~mm}$ (Mok et al., 2018; Mok et al., 2019). (a)

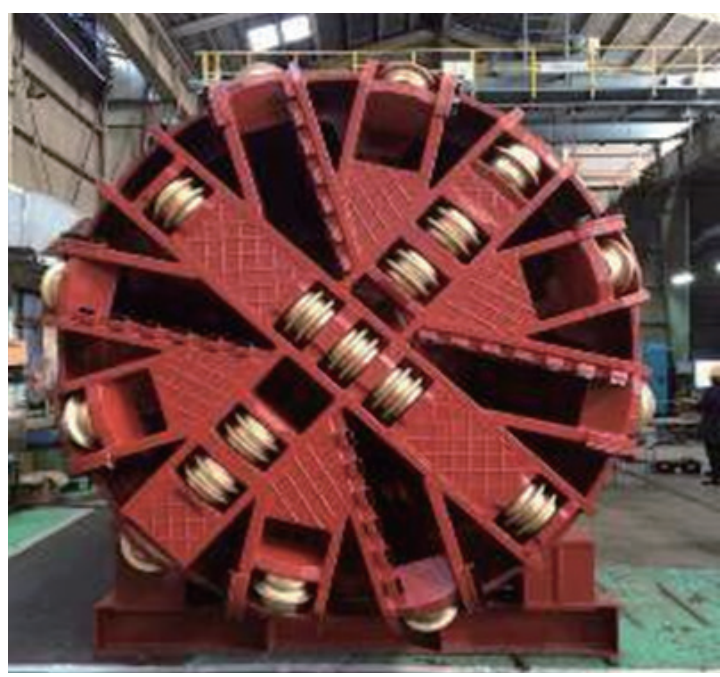

(b)

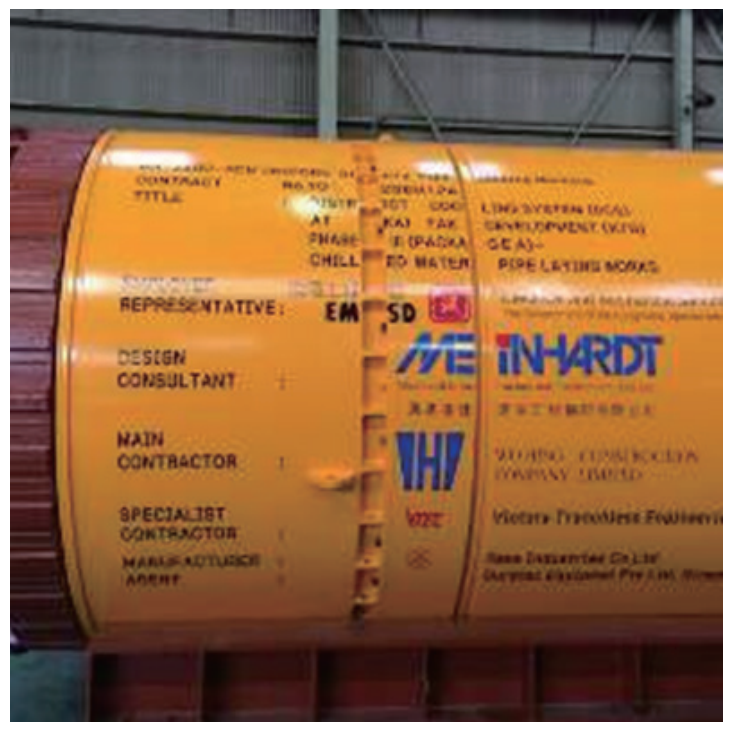

Figure 1. Appearance of the TBM: (a) Front view (courtesy of VTEC) and (b) Side view (courtesy of VTEC). 


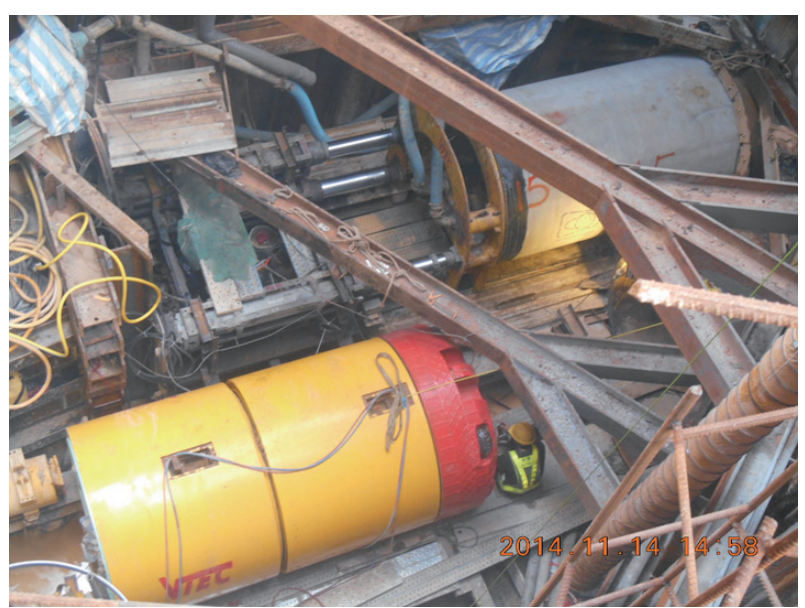

Figure 2. Running two TBMs in parallel (courtesy of VTEC).

\subsection{Construction of a hand-dug tunnel from the receiving pit to receive three $\mathrm{TBMS}$}

In the Kai Tak project, as constrained by existing utilities and other features, the designed location of a receiving pit was relocated in the construction stage, resulting in insufficient space for TBM entry in an acute angle. To rectify the situation, a short section of hand-dug tunnel was constructed from the pit. It used horizontal pipepiles as tunnel lining, with grout to form an impermeable layer in the ground, and sheet-piles as stopper at the far end. Steel lagging plates were installed against pipe-piles as lining to enhance structural stability when tunnel excavation was proceeded. Receiving eyes were cast to allow three TBMs (one 1,200 $\mathrm{mm}$ and two $1,500 \mathrm{~mm}$ in diameter, in triangular configuration) to enter the tunnel according to their original alignment. The TBMs were pulled to the relocated receiving pit, one after another, for lifting to ground surface (Mok et al., 2018; Mok et al., 2019).

\subsection{Skinned-off of TBM body in receiving pit for retrieval}

Due to constraints caused by placement of utilities in the pit, the available clearance between utility crossings was insufficient to allow hoisting the TBM to ground surface. A technique to skin off the outer ring of the TBM had been adopted in the Kai Tak project, such that its size $(2,800 \mathrm{~mm}$ in diameter) was reduced for retrieval through the available opening using the vertical lifting method (Mok et al., 2018; Mok et al., 2019).

\subsection{Construction of $650 \mathrm{~m}$ pipeline in mixed ground conditions in a single drive}

In a DSD project at Tung Chung, a $650 \mathrm{~m}$ rising main of 1,200 $\mathrm{mm}$ in diameter was constructed using a 1,650 $\mathrm{mm}$ diameter slurry-operated TBM in a variable and alternating ground composed of completely decomposed granite (CDG), slightly decomposed granite (SDG) bedrock, and CDG mixed with SDG, adjacent to the North Lantau Highway. Mild steel pipes of $3 \mathrm{~m}$ in length and $22 \mathrm{~mm}$ thick with a flexible joint were used to construct the sleeve pipeline (Figures 3 and 4).

Based on laboratory tests, the CDG has an internal angle of friction of 35 degrees and the SDG has strengths of $320-350 \mathrm{MPa}$.

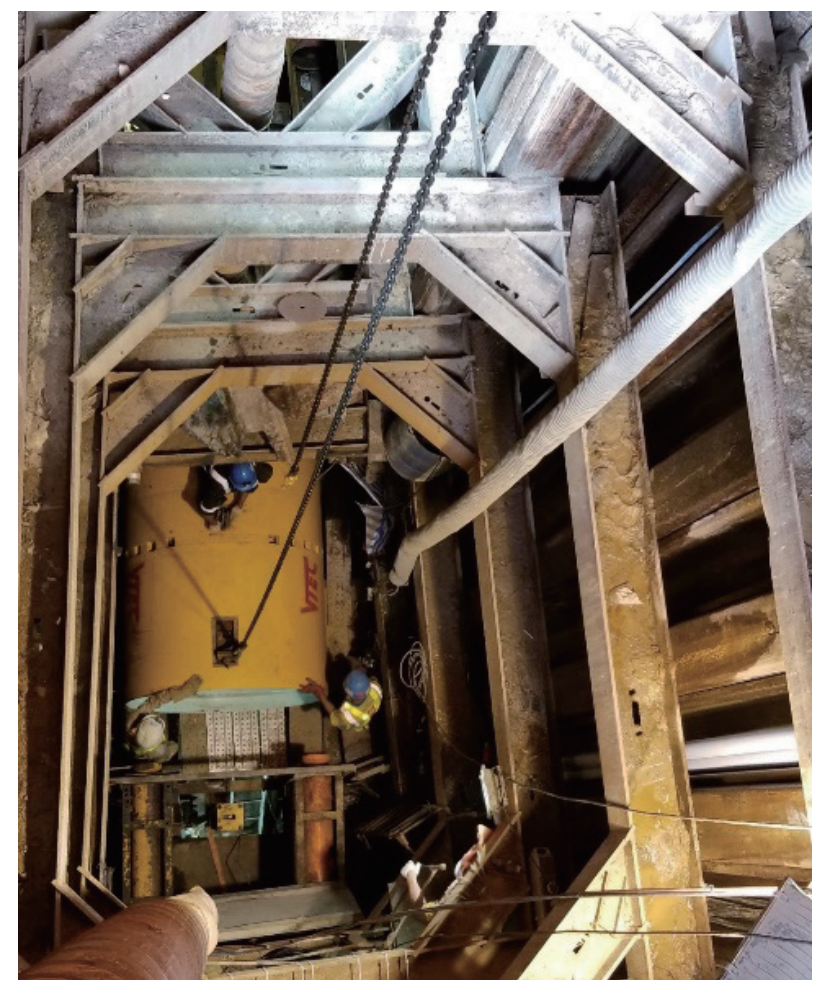

Figure 3. Positioning of the TBM in the jacking pit (courtesy of VTEC).

With a face access to change damaged disc cutters, the TBM was equipped with a compressed air chamber, four intermediate jacking stations (IJS) and a fully programmable volume-controlled automatic lubrication system with 40 stations. The first IJS was located $30 \mathrm{~m}$ from the rear of the TBM and other IJSs were $150 \mathrm{~m}$ apart. A gyroscopic guidance system with laser theodolite was used to check the tunnel alignment in the course of driving (Figures 5 and 6). 


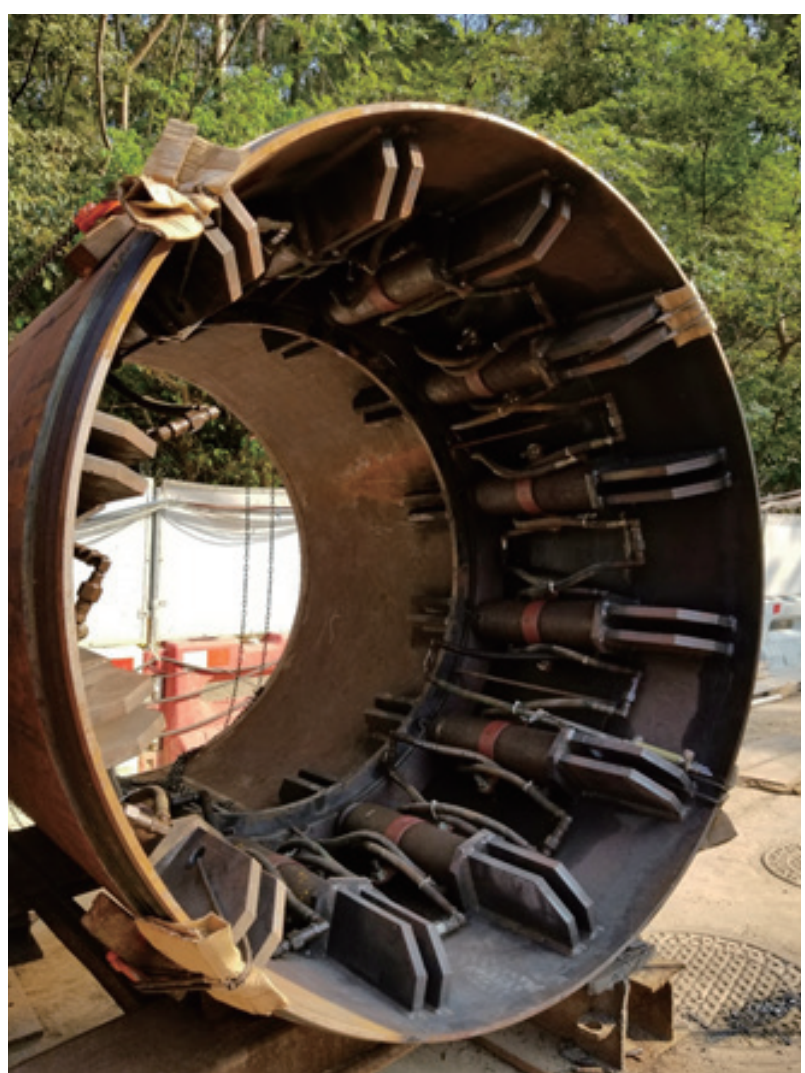

Figure 4. Appearance of the IJS (courtesy of VTEC).

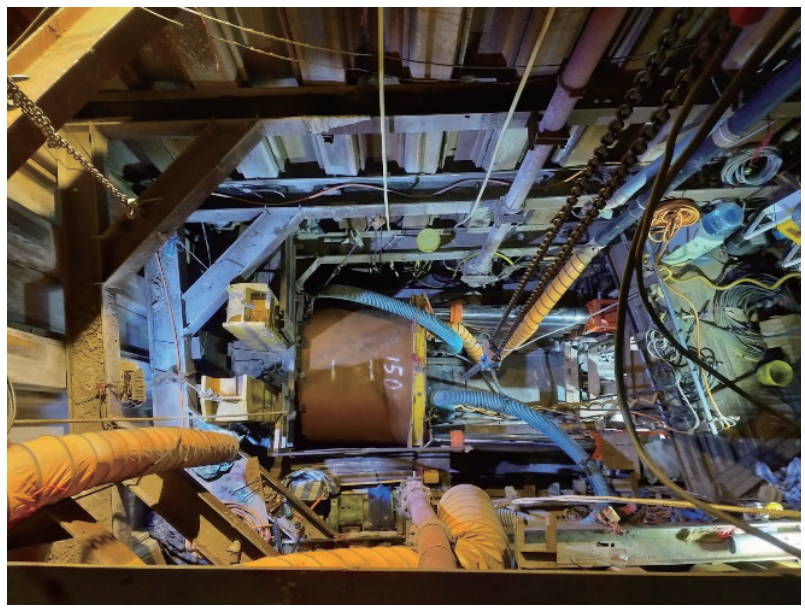

Figure 5. Pipejacking in operation (courtesy of VTEC).

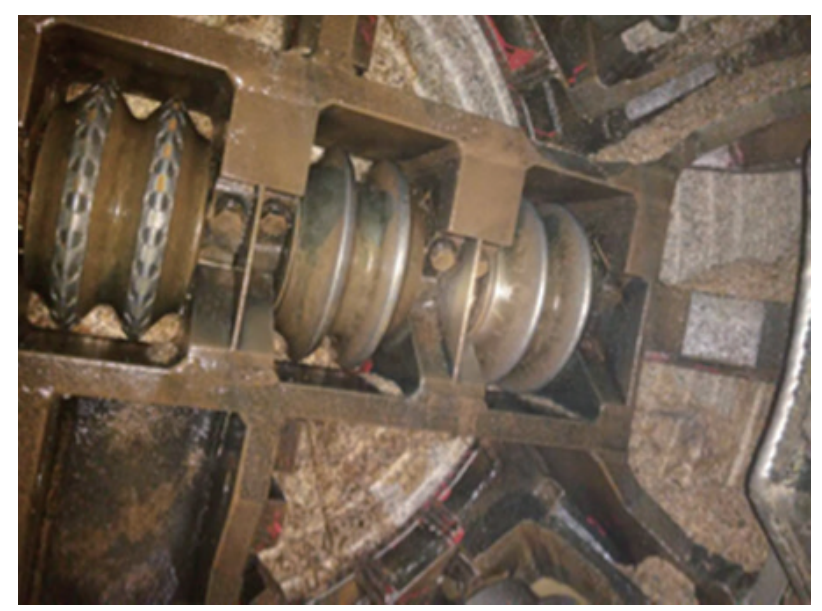

Figure 6. Appearance of the disc cutters and rock face (courtesy of VTEC).

The depth of overburden is about $5.6 \mathrm{~m}$ and increases to $16 \mathrm{~m}$ below a hilly terrain. The TBM advancement in rock was $10 \mathrm{~mm}$ per minute. The daily output rate was $2 \mathrm{~m}$ in rock and 5-6 m in soil and mixed ground. Disc cutters were changed for 25 times, averaging $20 \mathrm{~m}$ of TBM drive length each time. No abnormality was observed in the course of work.

\subsection{Retractable TBM}

Due to the presence of congested utilities underground and other site constraints such as structures, roads, etc., some locations would not have sufficient space to construct a receiving pit large enough to receive the TBM after completing the pipejacking drive. A retractable TBM which allows the cutterhead to be lost ring (Figure 7a) or foldable (Figure 7b) needs to be adopted. The inner ring of the TBM is detached from the outer ring for pulling to the jacking pit by installing a wire or thread bar with a hydraulic jack and spread beam in the jacking frame. The outer ring of the TBM is left to form part of the tunnel lining. To carry out the work, thin-wall pipe like mild steel or glass-fiber reinforced plastic (GRP) needs to be used to construct the pipeline (tunnel) so that there is sufficient clearance between the retracted TBM body and the tunnel for the pulling operation (Figure 8). This technique has been used in some pipe arch projects for short tunnel construction in recent years. 
(a)

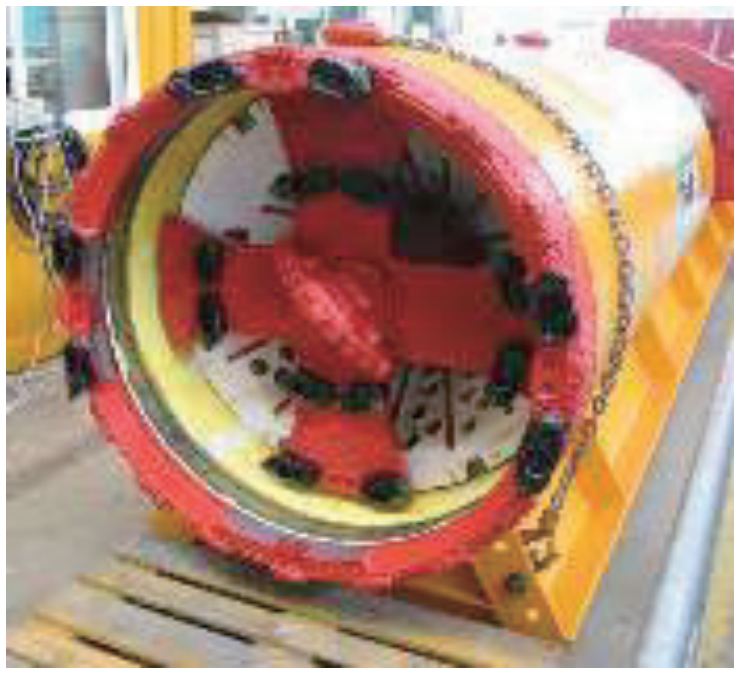

(b)

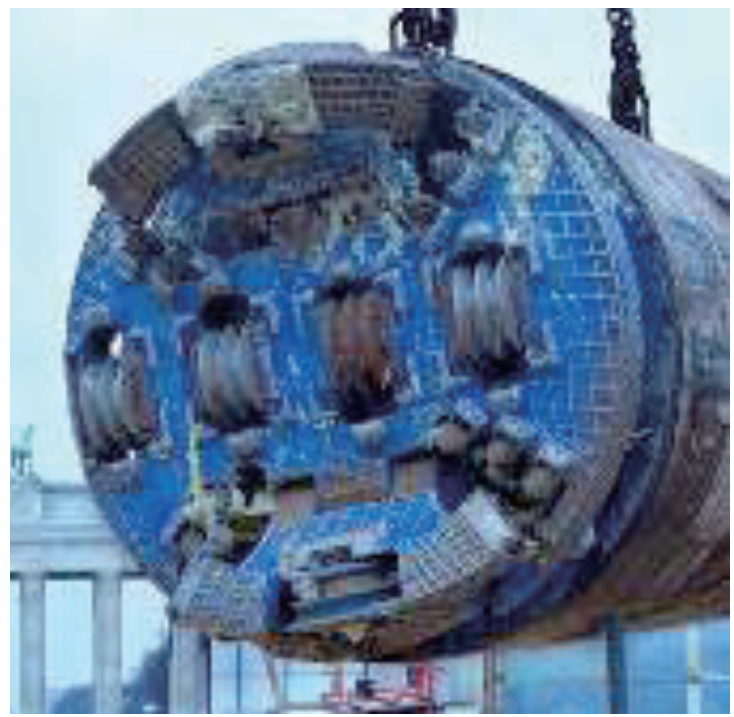

Figure 7. Retractable TBM: (a) Lost ring type (Herrenknecht, no date) and (b) Foldable type (Herrenknecht, no date).

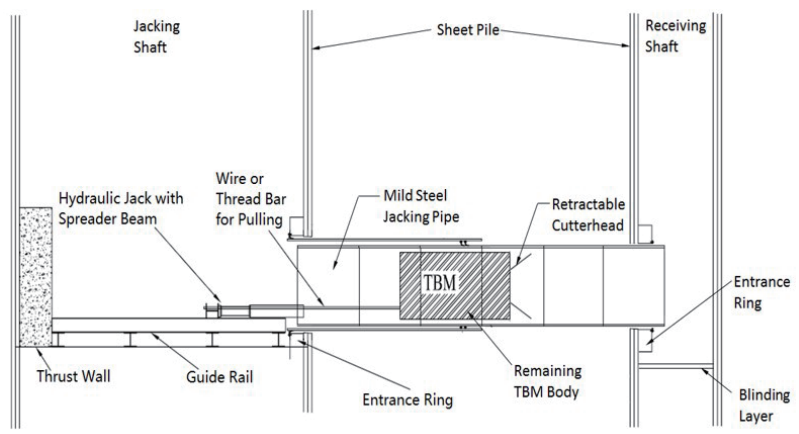

Figure 8. Pulling the TBM to the jacking pit after folding its cutterhead.

It has also been applied to act as a casing pipeline at the start and end points for horizontal directional drilling
(HDD) operations due to the difficulties of maintaining the pipeline in a smooth profile in ground with a high content of boulders, cobbles, and gravel (Figure 9).

This type of TBM is, however, uncommon in the market and must be ordered from the manufacturer when used.

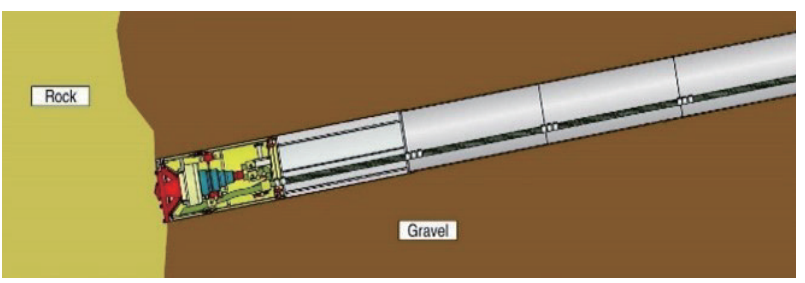

Figure 9. Installation of casing pipe for HDD operation (Herrenknecht, no date).

\subsection{Rectangular Tunnel Boring Machine (RTBM)}

This technique was developed in Japan in the 1970s and has been widely used in China and Singapore in recent years.

Making use of the earth pressure balance principle, this type of TBM is suitable in soft ground with occasional boulders and cobbles. The size and shape of a TBM can be tailored to suit the needs of the project, appearing in a square or rectangle. The front of the TBM is made by one to two main cutterheads of a fan type at the center and a number of smaller cutterheads at other locations (Figure 10).

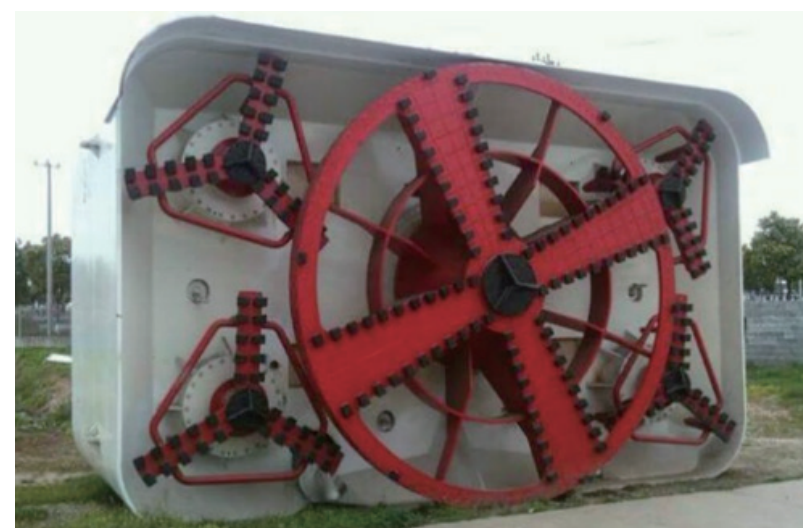

Figure 10. Appearance of a typical RTBM.

Thrust cylinders remain in the jacking pit and push forward the entire box segment. New segments are installed within the pit as the TBM advances (Figure 11). 


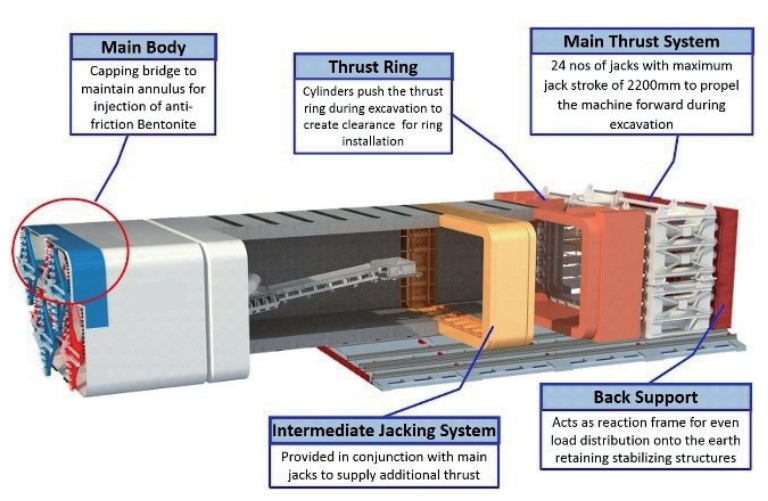

Figure 11. Side elevation showing the configuration of a typical RTBM.

As the TBM cuts through the ground, it turns the excavated material into a paste that is used as pliable, plastic support medium, to balance the pressure conditions at the tunnel face. The position of the TBM and box sections behind are controlled by the steering cylinders installed between the front and rear shields. Overcut formed by the TBM, generally $10-15 \mathrm{~mm}$, is filled up with lubricant and grout with a strength equivalent to the overburden pressure upon completion of the TBM operation. Additives for soil conditioning are injected into the excavation face when the TBM advances. It helps to form the soil plug in the screw conveyor so that the face pressure can be maintained.

The excavated material is removed to a trolley system through a screw conveyor installed in the TBM for transportation to the jacking pit and lifting to ground surface (Figure 12). Short sections of precast concrete segments are used to suit the limited size of the pit. It forms the tunnel lining which also serves as the wall of the tunnel (Figure 13). Depending on the size of the TBM, more than one screw conveyor may be required. The ground settlement induced is generally less than $10 \mathrm{~mm}$ based on the completed projects.

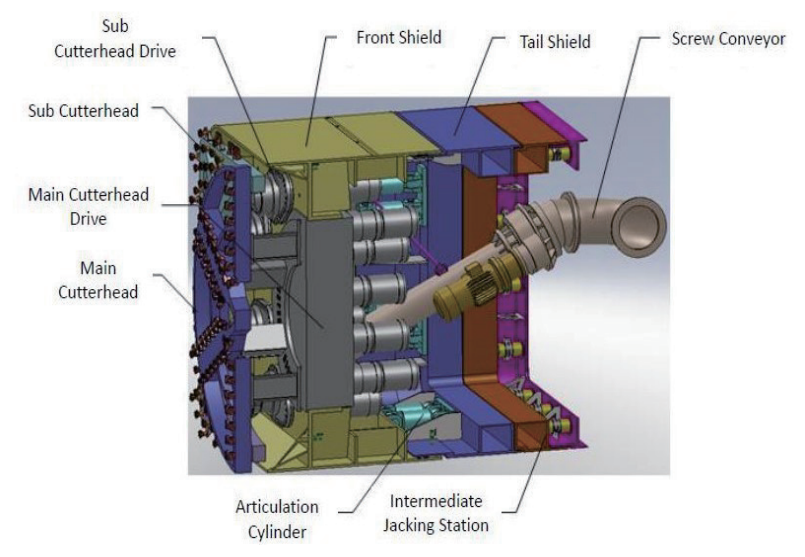

Figure 12. Side elevation showing the cutterheads, front and tail shields of a RTBM.

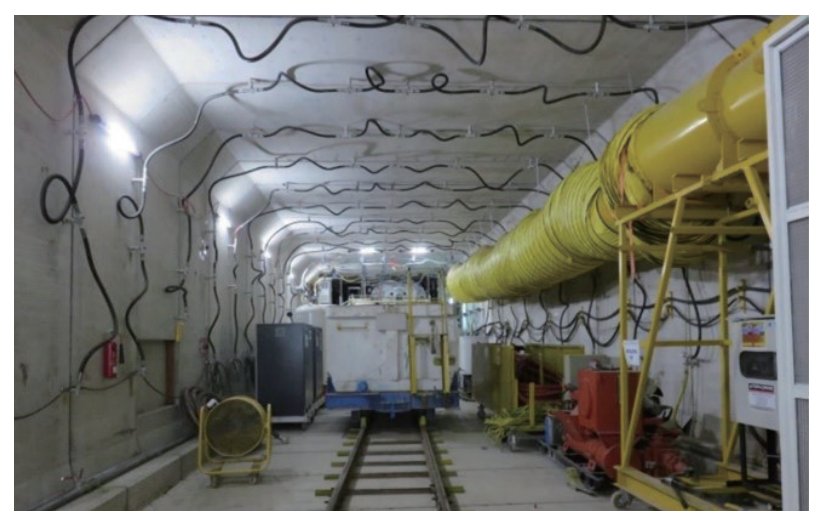

Figure 13. Condition of a tunnel formed by RTBM.

RTBM was introduced to Hong Kong for construction of a pedestrian subway in a government contract in 2020 .

A $3.9 \mathrm{~m} \times 2.8 \mathrm{~m}$ subway, $140 \mathrm{~m}$ long, was constructed using a 5,020 $\mathrm{mm} \times 4,020 \mathrm{~mm}$ and $4.5 \mathrm{~m}$ long RTBM, at a depth of $6.6-9 \mathrm{~m}$ from the jacking pit to the receiving pit. The ground comprised fill, alluvium and CDG with boulders at isolated locations. The RTBM was equipped with a compressed airlock chamber, allowing inspection of the ground ahead of excavation and removal of obstructions, if any, under a hyperbaric environment. Precast concrete segments of $1.5 \mathrm{~m}$ in length with a thickness of $500 \mathrm{~mm}$ were used as tunnel lining.

At the virtual site visit, it was noticed that the RTBM experienced difficulties in cutting through sizeable boulders. The situation was rectified after enhancement of the TBM cutterheads by installing more cutting bits to increase the cutting capacity. A steel frame was also installed at the rear of each of the two lower cutterheads to avoid blockage. Such works were carried out in the intermediate pit for construction of the permanent ventilation shaft.

The jacking speed was about $40-50 \mathrm{~mm}$ per minute. The ground settlement was in the range of $5-$ $12 \mathrm{~mm}$, within the tolerated value. Including the time for enhancement, the average daily production was 1.4 segments per day.

\subsection{Pipe arch/roof construction}

TBM pipejacking can be applied to pipe arch/roof construction for short and large tunnels using mini-TBMs in diameters of $1,000-1,200 \mathrm{~mm}$. In the Airport Authority Project in Tung Chung, 26 pipelines (each $27 \mathrm{~m} \mathrm{long}$ ), constructed by four 1,200 mm diameter slurry-operated TBMs, formed a pipe roof that was to serve a $50 \mathrm{~m}$ x $20 \mathrm{~m}$ luggage logistic tunnel. The work was carried out in rock fill after the completion of advanced grouting. The depth of the pipelines is $6 \mathrm{~m}$ below the railway track. Four TBMs, one from Herrenknecht and three from Rasa, were operated simultaneously at every fourth pipeline interval to minimise disturbance to the overlying ground during the jacking operation. Mild steel pipes of $22 \mathrm{~mm}$ thick and $6 \mathrm{~m}$ long 
were used. The clearance between each pipeline is $300 \mathrm{~mm}$, and the deviation in horizontal and vertical alignments was controlled within $20 \mathrm{~mm}$. Due to the requirement of night work, each pipeline took 10 nights for completion. Each completed pipeline was filled with cement grout to increase the structural stability. Three grout holes were provided in each pipe for lubrication. The maximum recorded ground settlement was $4 \mathrm{~mm}$. All four TBMs performed satisfactorily (Figures 14 to 17).

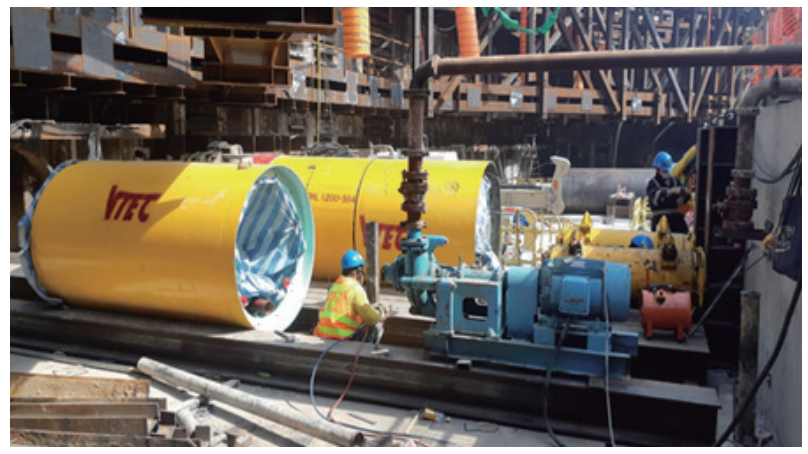

Figure 14. Set-up of TBMs in the jacking pit (courtesy of VTEC).

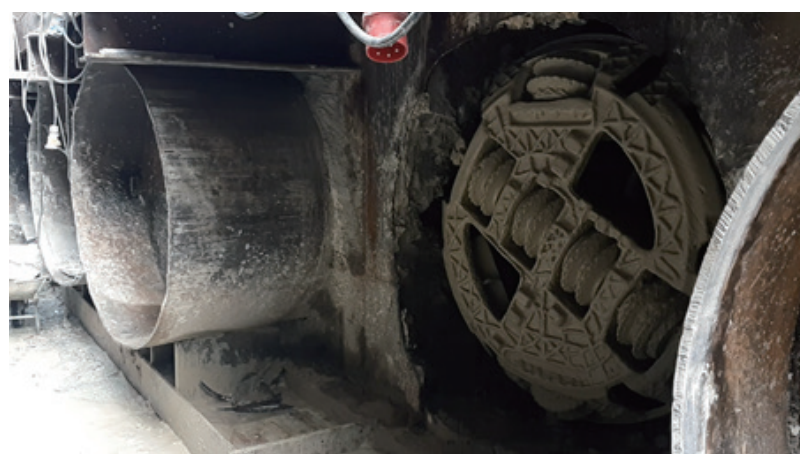

Figure 15. TBM arriving at the receiving pit (courtesy of VTEC).

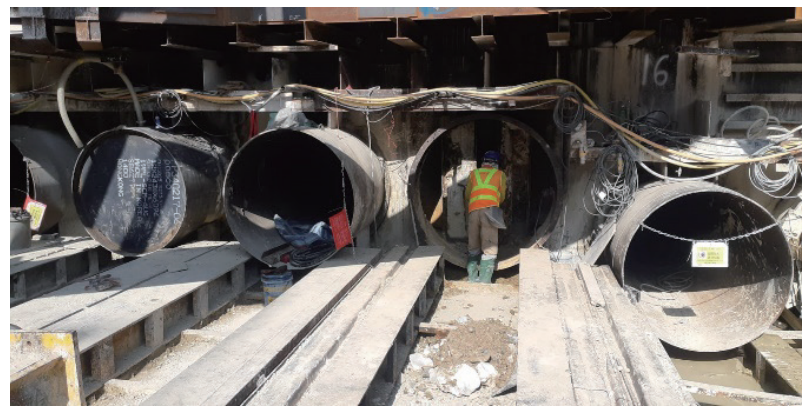

Figure 16. Preparation of the receiving eye for TBM entry (courtesy of VTEC).

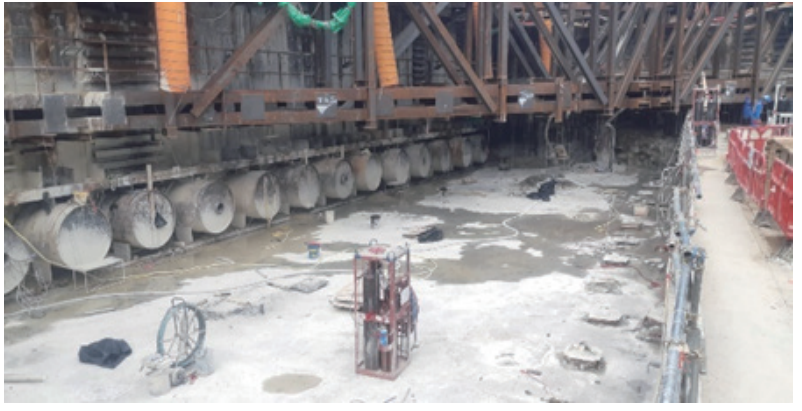

Figure 17. Completion of pipe roof construction (courtesy of VTEC).

\subsection{Construction of submarine intake and outfall pipelines}

Due to advancements of TBM technology enabling long drives, pipejacking can be adopted for construction of submarine intake and outfall pipelines from a jacking pit, through irregular terrain and complicated geological profile, to the seabed. The size of TBMs that can be used ranges from 1,500 - 2,500 mm. The configuration of TBMs and operations is basically similar to traditional TBMs except that a compressed airlock chamber needs to be installed for carrying out works such as disc cutter changes in a hyperbaric environment.

The depth of the pipeline in seabed determines the method of retrieving the TBM after completion of the work. For shallow depths, generally in soft marine deposit, an open trench method is used, in which the material on top and at the sides of the TBM is removed by divers using compressed air, and the TBM is hoisted to a barge (Figures 18 and 19). This method requires the TBM body to be detached from the pipe string behind, and the provision of a watertight bulkhead at the end of the rear shield. The support of the TBM and pipeline in the underlying material, using a method such as deep cement mixing and stone columns, is required to ensure stability during and after the driving. Further details can be found in many reference sources. For greater depths, in which the TBM emerges in firm material like alluvial sand, construction of a receiving pit is a common approach, using pipe-piles as temporary works. The pipe-piles ensure penetration through all materials to the required depth. To avoid excavated material, which might be contaminated, from escaping into the sea during excavation, sheet-piles are driven to encompass the perimeter of the pipe-piles down to the formation level. Excavation is carried out inside the pit and the excavated material is removed to the barge parking aside. The TBM is then retrieved in the pit (Figures 20 and 21). 


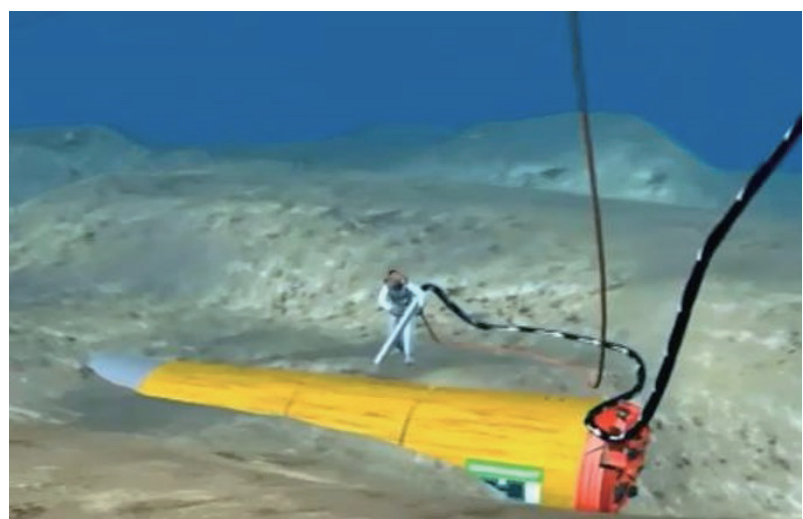

Figure 18. Excavation of an open trench in the seabed (Herrenknecht, no date).

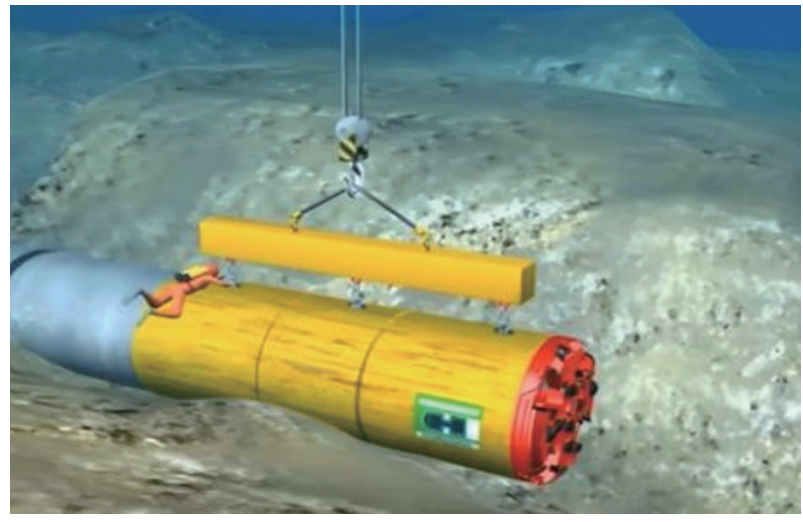

Figure 19. Hoisting of a TBM from an excavated trench to a barge (Herrenknecht, no date).

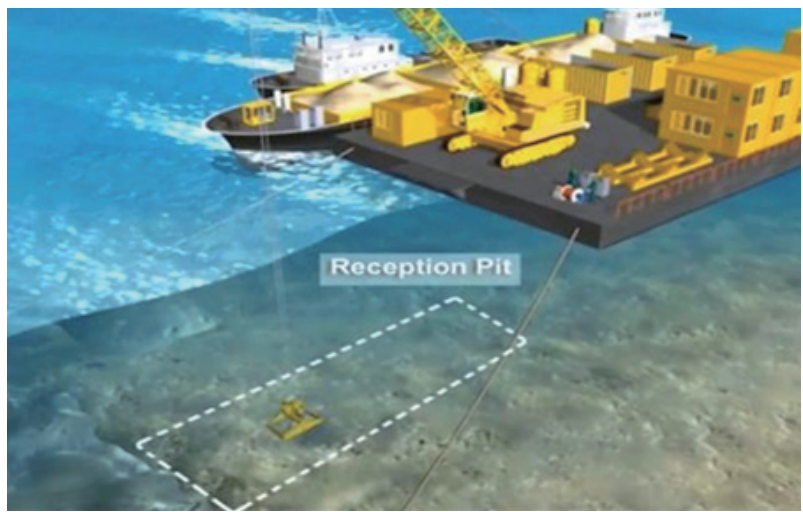

Figure 20. Excavation in a receiving pit (Herrenknecht, no date).

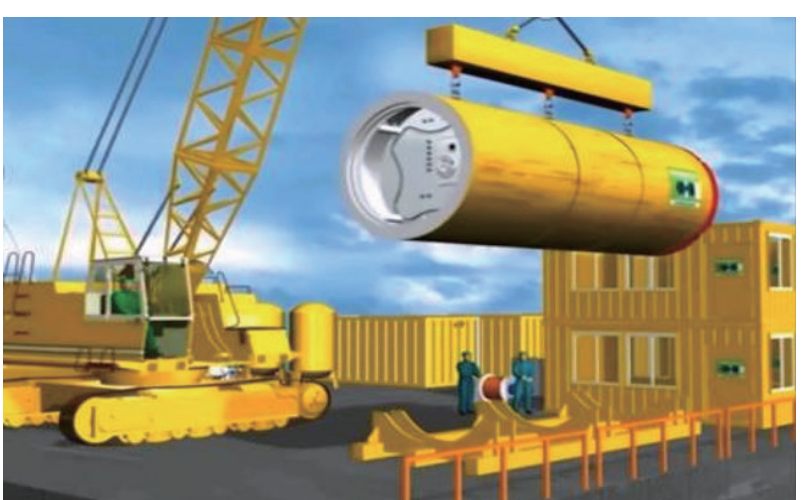

Figure 21. Appearance of a TBM after retrieval (Herrenknecht, no date).

\section{Construction of jacking and receiving pits as constrained by existing utilities}

Difficulties may be encountered when looking for a location for construction of a jacking/receiving pit free of existing utilities. Utility diversion is always unrealistic due to the long time required from planning to execution. It is therefore not uncommon that existing utilities are present at the pit locations. Construction of the temporary works by sheet-piles are generally used due to lower costs and faster operation. These could be driven to either side of existing utilities with a clearance roughly at $0.5 \mathrm{~m}$. To ensure structural integrity of the pit, steel lagging plates are provided at the window locations, one after another, below existing utilities and connected to the sheet-piles at both sides by welding, while excavation progresses. A grout curtain is formed by advanced grouting in the ground outside the windows by drilling vertical and different angles of inclined grout holes to prevent ingress of groundwater before commencement of the excavation.

\section{Size of the TBM and structural stability and integrity of the jacking/receiving pit}

The size, shape and orientation of a jacking/receiving pit would determine the size of a TBM adopted for the work. A large TBM may need to be replaced by a number of smaller TBMs to suit the limited size of the pit, or the available opening as constrained by utility crossings. The TBM arrangement depends on the size and number of TBMs, which could be configured in a triangle, square or trapezoidal shape. To eliminate any structural stability and integrity problems resulting from construction of launching eyes by cutting in sheet-piles and steel lagging plates, and the subsequent pipejacking works, a reinforced concrete wall is usually constructed in the front and at the rear against the temporary works in the full width of the jacking pit for the purpose of launching the TBMs and providing thrust, respectively. 


\section{Jacking pipe}

Precast concrete pipe is commonly used to construct a permanent pipeline or a sleeve pipeline for installation of small sizes of permanent pipelines due to its high strength and permissible axial load.

Mild steel pipe is used to construct sleeve pipelines for accommodation of smaller sizes of permanent pipelines in shallow depths. A flexible joint can be provided at the pipe to allow movement when encountering different ground conditions in the TBM driving, but its allowable angular deflection is less than that of the precast concrete pipe. Another type is GRP pipe, which is suitable for both storm drains and sewers. These two types of pipe are also suitable for pipelines constructed by retractable TBMs due to their thin walls, which provide sufficient space for the TBM pulling operation from the end of the completed pipeline to the jacking pit.

\section{Treated soil block for launching and receiving TBM}

Treated soil block, also called grout block, is required to be provided in the ground outside the launching eye and the receiving eye to support the TBM when it is pushed into the ground from the jacking pit and when it enters the receiving pit. It also enhances the ground stability and stops water ingress arising from the change of groundwater pressure when the launching/receiving eye is cut in the sheet-piles.

Grout hole spacing depends on the grout spread, which is a function of the porosity of the soil and the depth of drilling. The porosity of soil in Hong Kong ground conditions based on laboratory tests ranges from 0.3 to 0.4 . The grout spread from a grout hole is in the range of 400 to $500 \mathrm{~mm}$, based on site trials in some projects. For design purposes, 0.35 for the porosity of soil and $450 \mathrm{~mm}$ for grout spread are generally chosen. This gives an overlapping zone of $150 \mathrm{~mm}$ between grout holes at $600 \mathrm{~mm}$ centres. Assuming that the vertical alignment of grout holes is controlled to $1: 100$, there is zero overlapping at a depth of $15 \mathrm{~m}$. Therefore, at a greater depth, reduction of the grout hole spacing is required.

Bentonite cement grout mixed with sodium silicate is usually used to form the treated soil block (Mok et al., 2019). Bentonite controls the cracks and sodium silicate speeds up the setting time. In porous ground, polymer could be added to form an impermeable membrane bridging across the pores between soil particles to prevent ingress of groundwater. Microfine cement grout should be used in ground with a high content of clay for effective penetration.

To ensure the effectiveness of grout block, probe holes must be carried out at different locations on the sheet-piles. If leakage is found, re-grouting will be required.

\section{Cost of TBM pipejacking work}

(1) The cost in a project involves construction of the jacking and receiving pits, and TBM works. For pit construction, the ground conditions, such as soft ground, mixed ground and hard ground, determine the type of temporary works adopted.

(2) Sheet-pile is the most common type of temporary works adopted in homogeneous silty to sandy ground, due to lower costs and faster operation, but pre-boring is required at the locations of boulders.

(3) For ground with a high content of boulders, pipe-pile needs to be adopted. Perimeter grouting is required if the groundwater is high.

(4) For TBM works, the cost includes the TBM, its set-up on the ground and in the pits, and pipe material; and the risk that the contractor is willing to accept, which depends very much on constraints and hence difficulties, as well as ground conditions likely to be encountered in the course of driving.

(5) The type of cutterhead, set-up in the front and rear shields, requirement of a compressed airlock chamber, and of a telescopic jacking cylinder, navigation system, type of supporting medium in the tunnel face, a number of lubrication systems and ports, type of lubricant, a number of intermediate jacking stations, geotechnical instrument monitoring, length and profile of a drive, number of drives, etc., will greatly affect the cost of the TBM works.

(6) If the size is available in the local market, the cost of a TBM will certainly be much cheaper that ordering a new TBM from the manufacturer. Therefore, the cost of TBM pipejacking works could vary significantly in different projects, even though the same size of TBM is used.

(7) Based on previously completed projects, TBMs manufactured in Japan are generally 20 percent to 30 percent cheaper than those from Germany due to lower transportation costs and simpler configuration.

\section{Prospects for TBM pipejacking work}

There is an increasing demand for the use of TBM pipejacking techniques for construction of pipelines and other underground structures. This is due to construction difficulties, lack of space for opening trenches as constrained by existing utilities, structures and traffic, and stringent requirements imposed by the Labour Department on the use of hand-dug tunnels.

At present, TBM pipejacking works in many projects have been designed for construction at depths exceeding 8 $\mathrm{m}$ below ground to avoid conflict. Construction of pipelines 
using small TBMs, of $600 \mathrm{~mm}$ to $800 \mathrm{~mm}$ in diameter, has been noted at some locations, at shallow depth above existing utilities or underground features such as box culverts and pedestrian subways.

Rapid development in pipejacking TBM technology has minimised the problems encountered. Retractable TBMs can be used for constructing pipelines where finding a location for the receiving pit has been difficult or impossible, as noticed in a DSD project. Rectangular TBM technology for construction of pedestrian subways is promising in the completed project and likely to be adopted again in future projects. This technique can also be applied for construction of underground water storage tanks and the like in urban area to alleviate the flooding problem in rainy seasons.

\section{Some observations}

(1) Improper TBM type selection, including a cutterhead incapable of cutting through the ground encountered efficiently and effectively, has in some cases caused a stoppage by obstruction.

(2) Improper positioning or an insufficient number of intermediate jacking stations could result in insufficient force to push the section of pipeline in front forward.

(3) Insufficient and improper lubricant to fill up the overcut formed by the TBM could lead to rapid closing of the annulus space, causing soil friction to develop on the pipeline, which requires high jacking force and could damage jacking pipes. A suitable form of lubricant should be provided to fit the ground conditions encountered.

(4) Failure of the grout curtain in the ground outside jacking and receiving eyes, due to a lack of or insufficient overlapping in grout spread from grout holes, would result in significant ingress of groundwater and ground subsidence. Grout design should be based on soil properties revealed by laboratory testing results.

(5) Slurry that escapes to the ground surface due to porous ground could encroach into the ducts of existing utilities, causing blockages. Thickening the slurry can minimise such occurrences.

(6) Excessive ground settlement due to adverse ground conditions could lead to damage to utilities and structures within the settlement influence zone.

(7) Out-of-tolerance vertical and horizontal alignments in a pipeline could make the asbuilt pipeline appear to have an irregular profile and reduce its usable space. Hence, the design should make allowances for such issues.

(8) Apart from drilling at the jacking and receiving pit locations and given the problems in finding other locations for drilling at ground level, horizontal drilling by means of steerable horizontal directional coring (HDC) can provide data to determine ground conditions in the pipeline alignment, thus minimising the risk of TBM stoppage due to obstruction.

(9) Two TBMs running in parallel from a jacking pit has proved to be a mean of speeding up progress with the ground settlement controlled within tolerance.

(10) A $1 \mathrm{~m}$ clearance is considered adequate for pipelines passing through a ground with piled foundations and existing utilities as a safe margin.

(11) Long curved alignment is achievable to overcome the utility or site constraints which limit the locations of jacking and receiving pits.

(12) Some of the Intermediate jacking stations in a drive may not need to be activated because of the effect of lubricant in the annular space formed by the TBM.

(13) A change of a receiving pit location and size due to utility or site constraints in the construction stage could cause the TBM to enter the pit at an acute angle, resulting in an inability to retrieve the TBM for lifting to the ground surface due to insufficient room. Construction of a short length of hand-dug tunnel using horizontal pipe-piles as tunnel lining from the relocated receiving pit could resolve the problem.

(14) For shallow pipelines, TBM crossing would likely cause ground movement exceeding tolerances and affecting the utility undertakings and road users. Advanced grouting could be an effective mean to minimise the problem.

(15) Lifting of the TBM to the ground surface from a completed permanent concrete shaft with a clearance of $100 \mathrm{~mm}$ has been demonstrated to be viable without causing damage to the shaft wall.

(16) Construction of a pipeline at a depth below 8 to $10 \mathrm{~m}$ or more to suit utility and other constraints is not uncommon. High consumption of cutting tools should be expected due to the likelihood of encountering more hard materials in a deeper ground.

(17) Hong Kong ground conditions are highly variable in small distances. A TBM could be stuck in the ground due to natural or artificial obstructions. A rescue operation by means of a rescue pit or a rescue tunnel for the removal of obstructions and the inspection of damage in the cutterhead is time-consuming and expensive. A sonic probing soft ground device that gauges density contrast in different materials should be installed in the TBM if the size permits. This enables the TBM operator to take necessary 
action in advance if obstructions exist in the ground.

(18) Due to the congestion of existing utilities and other site constraints, it may not be possible to find a space for construction of a receiving pit with a size large enough to retrieve the TBM after completing the work. Retractable TBMs appear to be a solution.

(19) The use of a retractable TBM is limited to a straight or slightly curved alignment and certain sizes, generally not exceeding $150 \mathrm{~m}$ in length or $2,500 \mathrm{~mm}$ in diameter. This is because of its heavy weight, which requires large sizes of thread bar connecting to the jacking frame for the pulling operation. A lost ring type of cutterhead is suitable in homogeneous silty to sandy ground.

(20) At jacking and receiving pit locations with congested utility crossings in which their diversion is impracticable, a large TBM may have to be replaced by a number of smaller TBMs. This results in the pipelines being aligned in more than one layer, to suit the available space constrained by utilities.

(21) Through the advancement of TBM technology in alignment control and capacity for long drives, the location of jacking and receiving pits can be selected in a more flexible manner, such that their numbers and construction difficulties due to site constraints could be reduced. Intermediate pits would not be required unless used to construct permanent chambers for future maintenance.

(22) The daily production rate of a TBM depends on the type of TBM selected, ground conditions encountered, downtime due to maintenance, positioning of pipes, change of damaged cutting tools, survey checking, etc. It could vary significantly from $3-5 \mathrm{~m}$ in hard ground, 6 $-8 \mathrm{~m}$ in mixed ground, and $10-12 \mathrm{~m}$ in soft ground, within a nine-hour shift.

(23) The pipe roof or arch technique for short tunnel construction using mini-TBMs has been demonstrated to be effective by virtue of accurate alignment control and minimal ground disturbance. Apart from traditional TBMs, retractable TBMs can also be used if no receiving pit is constructed. The foldable type of cutterhead is appropriate for multi-pipeline construction.

(24) The RTBM successfully completed pedestrian subway construction but the cutterhead arrangements encountered difficulties in cutting through sizeable boulders, and the gap between the two lower cutterheads and the bottom of the TBM was easily trapped by debris. The design of the cutterheads, including the type, number, and position of cutting tools, needs to be reviewed and modified so that the cutting capacity and efficiency can be improved to suit Hong Kong's highly variable ground conditions.

(25) Based on the DSD's Research and Development Report (Drainage Services Department, 2002 ), about $10 \%$ of the pipejacking drives experienced problems such as excessive ground settlement, road collapse, or the TBM stuck in the ground. It is hoped that through the continuous development of pipejacking TBM and experience of TBM operators, this situation can be improved.

\section{Conclusion}

(1) TBM pipejacking appears to be a viable and effective solution to deal with utility congestion and other constraints, which is a common phenomenon in urban areas that limit the use of open trench excavation. Many construction problems could be avoided if such constraints are identified and resolved in an early stage. This minimises contractual matters which could lead to additional expenditure and delay of works.

(2) Most of Hong Kong has ground conditions that are highly variable in short distances. Special and innovative techniques to deal with different scenarios are required in each project to suit the needs encountered. These techniques are continually being refined and developed.

(3) Improvements cover both larger and smaller diameters, longer drives, better control of alignment, faster and curved driving, more durable cutting tools, accurate location of underground utilities, provision of a sensor device in TBMs to detect obstructions ahead of excavation, different ground conditions, the ability to work deeper under water and hard ground, and better settlement control.

(4) There are also certain other constraints, such as lack of or insufficient room for construction of jacking and receiving pits at suitable locations due to congestion of existing utilities and thus lack of space for their diversion, proximity to shops, insufficient clearance between overlying utilities and the TBM pipeline, and unexpected underground artificial obstructions. These factors limit the application of TBM pipejacking techniques. 


\section{Acknowledgments}

The authors wish to express their gratitude to Victory Trenchless Engineering Company Limited (VTEC) for providing some of the technical data and photographs from the respective projects for this paper. Special acknowledgement is given to Herrenknecht AG for permission to extract relevant information and photographs from technical brochures in making this paper.

\section{Notes on contributors}

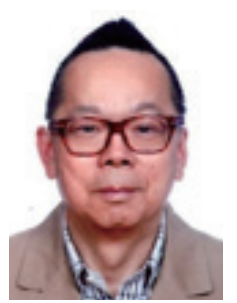

Ir Wilson W S Mok graduated from the University of Windsor in Canada and has over 42 years of practical working experience in a wide variety of geotechnical and civil engineering projects in both design office and site. He is a chartered civil and geotechnical engineer. He is also a Fellow of The Hong Kong Institution of Engineers, the Institution of Civil Engineers, and the Chartered Institution of Civil Engineering Surveyor. He specialises in geotechnical investigations and instrumentation, deep excavations, pipejacking, tunnels, ground improvements, settlement analysis, reclamation, site formation, slope preventive measures, foundations and sewerage works. He has been involved in the design, construction supervision and administration of more than 24 kilometre-long pipeline construction projects in the urban areas of Hong Kong, using different types of trenchless techniques. He is the author/co-author of several technical papers in this aspect, and his paper titled "Sewer installation by pipejacking in the urban areas of Hong Kong", in two parts, has been awarded the HKIE Transactions Prize 2007. His paper "Challenges in Construction of the Phase IIIA District Cooling System in Kai Tak" received the Overall Best Award from ACEHK in 2017. He is currently an independent consultant for trenchless works.

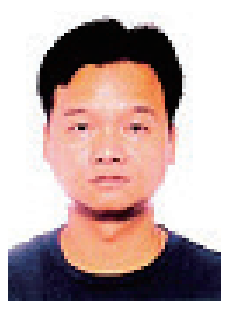

Ir Andrew S W Ng graduated from Coventry University in the United Kingdom in 1992. He has over 25 years of construction experience in a wide range of civil engineering projects including road, water and drainage works, and pipe works for tunnel support. He is a chartered engineer, with membership in The Hong Kong Institution of Engineers and the Institution of Mechanical Engineers. He has been involved in trenchless construction works for various drainage and utilities installations by tunnel boring machines and other techniques for projects in government and the private sector since 1996. $\mathrm{He}$ is the founder of Victory Trenchless Engineering Co., Ltd., which provides solutions to construction projects of using different trenchless techniques.

\section{References}

[1] Mok W W S (2006). Straight or Curved Sewers? Pipejacking Options in Hong Kong. In: HKIE GDC Annual Seminar.

[2] Mok W W S, Mak M K W and Poon F H T (2007). Sewer Installation by Pipejacking in the Urban Area of Hong Kong: Part I - Planning, Design, Construction and Challenges. HKIE Transactions, 14(1), pp. 17-30.

[3] Mok W W S, Mak M K W and Poon F H T (2007). Sewer Installation by Pipejacking in the Urban Area of Hong Kong: Part II - Performance of Works, Lessons Learned and Improvements Proposed. HKIE Transactions, 14(1), pp. 31-43.

[4] Mok W W S (2007). Pipejacked Tunnels - What to do If a Tunnel Boring Machine is Stuck in Ground? In: Trenchless Conference in Macau. Macau.

[5] Mok W W S, Mak K W (2009). Tunnelling and Pipejacking Techniques for Trenchless Installation of Drainage Pipelines. HKIE Transactions, 16(2), pp. 1-12.

[6] Mok W W S, Lo V K Y and Chau G T M (2016). Trenchless Construction for District Cooling System (DCS) in a Smart City: A Case Study on Kai Tak Development in Hong Kong. In: Trenchless Conference in Hong Kong. Hong Kong.

[7] Mok W W S (2017). Challenges in Construction of the Phase IIIA District Cooling System in Kai Tak. In: Association of Consulting Engineers Hong Kong (ACEHK) Annual Award 2017.

[8] Mok W W S, Lo V K Y, Chau G T M and Lau L Y M (2018). Trenchless Construction of Phase IIIA District Cooling System (DCS) by TBM Pipejacking and Hand-dug Tunnelling on Kai Tak Development: Part I - Design and Construction Considerations. HKIE Transactions, 25(1), pp. 56-66.

[9] Mok W W S, Lo V K Y, Chau G T M, Lau L Y M (2019). Trenchless Construction of Phase IIIA District Cooling System (DCS) by TBM Pipejacking and Hand-dug Tunnelling on Kai Tak Development: Part II - The Challenges. HKIE Transactions, 26(1), pp.20-29.

[10] Mok W W S (2019). Innovative Pipe Installation by Trenchless Construction. In: CIC Competition 2019. Construction Industry Council.

[11] O' Reilly M P and New B M (1982). Settlement above Tunnels in the United Kingdom - Their magnitude and Prediction. In: Proceedings Tunnelling' 82 Symposium. United Kingdom: Institute of Mining and Metallurgy.

[12] Pipe Jacking Association, (1995). Guide to Best Practice for the Installation of Pipe Jacks and Microtunnels. United Kingdom, pp. 24, 44-56.

[13] Research and Development Section, (2002). Trenchless Pipe Installation and Renovation Techniques, Review of Pipe Jacking/Microtunnelling Techniques for Construction of Drainage Pipelines. Research \& Development Report No. RD 1005/2, Hong Kong: Drainage Services Department, Government of the Hong Kong SAR.

[14] The British Tunnelling Society and the Institution of Civil Engineers, (2000). Specification for Tunnelling. United Kingdom: Thomas Telford, pp. 36, 86-88 \& 106. 